Revista Temas Socio Jurídicos Vol. $38 \mathrm{~N}^{\circ} 76$ Enero - Junio de 2019

ISSN: 0120-8578

ISSN electrónico: 2590-8901

\title{
EL AMBIENTALISMO BRASILEÑO COMO FACTOR DE IMPEDIMENTO DEL DESARROLLO SOCIAL Y HUMANISTA EN LATINOAMÉRICA
}

\author{
Rilke Rithcliff Pierre Branco* \\ Recibido: Marzo 17 de 2019 \\ Aceptado: Mayo 2 de 2019
}

\begin{abstract}
RESUMEN:
Este artículo tiene por objeto presentar la función y utilidad del ambientalismo en general, con el especial énfasis que se le da en la Constitución Federal de Brasil al definir fundamentos, objetivos y características fenomenales para las prácticas más verdecentristas. El tema aborda las cuestiones reglamentarias y legales, así como un pilar crítico relevante: el Estado Ambiental como un factor político que impide el entero desarrollo humanista de América Latina.
\end{abstract}

Palabras clave: Constitución; políticas ambientales; desarrollos; Latinoamérica.

Citar este trabajo como: Pierre Branco, R. (2019). El ambientalismo brasileño como factor de impedimento del desarrollo social y humanista en Latinoamérica. Temas Socio-Jurídicos, 38(76), pp. 81-98. https://doi.org/ $10.29375 / 01208578.3580$

* Profesor del Centro Universitario de Brasil (UNIBRA), doctorando en Derecho de la Universidad de Buenos Aires (UBA), el autor es Máster en Derecho y Negocios Internacionales, MBA en Ciencias Políticas, Seguridad Laboral y Medio Ambiente, especialista en Derecho Constitucional, Derecho Administrativo, Derecho Civil, Derecho Tributario, Derecho Procesal, Derecho Deportivo, Gestión Pública y Legislación, con posgrado aún en Consultoría Empresarial, Historia, Geografía, Sostenibilidad, Portugués, Literatura, Inglés y Español en Brasil. Orcid: https://orcid.org/0000-0002-4019-719X. Correo electrónico: rilkepierre@hotmail.com 


\title{
BRAZILIAN ENVIRONMENTALISM AS AN \\ IMPEDIMENT TO SOCIAL AND HUMANISTIC DEVELOPMENT IN LATIN AMERICA
}

\begin{abstract}
:
The purpose of this article is to present the function and utility of environmentalism in general, with the special emphasis given to it in the Federal Constitution of Brazil by defining grounds, objectives and phenomenal characteristics for the more green-centered practices. The topic addresses regulatory and legal issues as well as a relevant critical pillar: the Environmental State as a political factor that impedes Latin America's full humanist development.
\end{abstract}

Keywords: Constitution; environmental policies; development; Latin America.

\section{O AMBIENTALISMO BRASILEIRO COMO FATOR IMPEDITIVO DO DESENVOLVIMENTO SOCIAL E HUMANÍSTICO NA AMÉRICA LATINA}

\section{RESUMO:}

O objetivo deste artigo é apresentar a função e utilidade do ambientalismo em geral, com ênfase especial na Constituição Federal do Brasil, ao definir fundamentos, objetivos e características fenomenais para práticas mais centradas no verde. $\mathrm{O}$ tema aborda as questões regulatórias e legais, bem como um pilar crítico relevante: o Estado Ambiental como fator político que impede todo o desenvolvimento humanístico da América Latina.

Palavras-chave: Constituição; política ambiental; desenvolvimento; América Latina.

\section{INTRODUCCIÓN}

Con un modelo ambientalista fisiocéntrico y como sede de la ECO-92, Brasil lideró en Latino América una tesis de proteccionismo ecológico que no cuida del humanismo relacional y laboral, que son reservas patrimoniales productivas y culturales de cualquier nación. Los gobiernos, la comunidad empresarial y académica de la región no entendieron la necesidad ni las ventajas de promover un enfoque centrado en las prioridades y prácticas multidisciplinares antropocéntricas del problema. Los sistemas y normas actuales no favorecen el progreso sostenible ni el crecimiento social. Como el "verdecentrismo" es un principio retórico de 
desarrollo que no respeta la lógica de los ciclos de civilización y la vida, la educación biopolítica de estos países debe avanzar.

\section{BREVE DEFINICIÓN DEL MEDIO AMBIENTE COMO DE- RECHO COMUNITARIO}

El medio ambiente se define como un sistema interdependiente de elementos que forman el conjunto de todos los bienes físicos naturales, que comprende también los valores culturales o artificiales que sean de uso común creados por el hombre o que estén de manera inalienable vinculados al planeta para proporcionar la vida de la humanidad.

Si bien el reconocimiento científico del medio ambiente se remonta a los estudios de Ernst Haeckel, fue Lester Brown en los años 80 quien usó la "sostenibilidad" como término para referirse a la explotación racional de los recursos que amenazan a las especies en la Tierra. Pero Vasak dijo que el derecho a un medio ambiente saludable y equilibrado es una garantía de $3^{a}$ generación, mientras hay estudiosos que sostienen que los derechos bioéticos son de $4^{\mathrm{a}}$ generación (Silva, 2005). Por otro lado, se supone y plantea la construcción de un razonamiento filosófico "del derecho a la felicidad" que corresponde a la $5^{\text {a }}$ generación, bajo la idea de formular una Jurisciencia que impulse un neocapitalismo antropocéntrico, que es objeto del derecho comunitario internacional.

\section{HISTORIOGRAFÍA Y PANEL GENERAL DEL DERECHO AMBIENTAL INTERNACIONAL}

Un rápido estudio de la historiografía muestra que, en las deliberaciones de 1972 en la Conferencia de las Naciones Unidas sobre el Ambiente Humano en Estocolmo, Suecia, se conceptuó el medio ambiente como un bien de naturaleza transindividual y difusa. Resultante de la preocupación efectiva de la humanidad frente a la degradación ambiental y el desequilibrio de la biota, la Comisión Mundial sobre el Medio Ambiente y Desarrollo, y la Comisión Brundtland de 1987, elaboraron un documento con el título Our Common Future 'Nuestro Futuro Común' (ONU, 1987), donde se consagró la expresión "desarrollo sostenible" en las ciencias. Ya en 1992, la Eco 92 o Cumbre de la Tierra realizada en Río de Janeiro, Brasil, fue el marco de las negociaciones internacionales sobre cuestiones del medio ambiente y desarrollo luego del surgimiento de una Declaración Universal en este hito y de otros tratados y protocolos sobre esta materia.

En este contexto se activaron diversos informes y sistemas de protección local, nacional y regional sobre el medio ambiente. Los derechos relativos a este asunto se elevaron al rango de valores esenciales para la supervivencia del hombre en la Tierra. Fue el inicio oficial de la doctrina "verdecentrista" o del "ecologismo". 
En este escenario geopolítico la ONU anunció los Objetivos de Desarrollo Sustentable (ODS) para el periodo 2015-2030, que tienen como base un estudio multidisciplinario (Sachs, 2015, p. 5). Posteriormente vino la Convención del Clima, el Programa 21, la Declaración de Río sobre el Medio Ambiente y el Desarrollo, el protocolo de Kioto de 1998, la Declaración de Principios para Bosques, el Convenio sobre la Diversidad Biológica, el Protocolo de Cartagena y la ratificación del Protocolo de Nagoya por los países sobre productos modificados genéticamente, entre otros instrumentos.

A nivel internacional las iniciativas de promoción de un movimiento a favor del fisiocentrismo se mantienen aún en el centro de la atención mundial. Se destaca el Plan Estratégico para la Diversidad Biológica 20112020 de la ONU, que busca alcanzar la Meta de Biodiversidad de Aichi con dicho objetivo del desarrollo del milenio. Todos ellos han sido preparativos en curso para las ediciones de la Perspectiva Mundial sobre la Diversidad Biológica (Perspectiva Mundial sobre la Diversidad Biológica, las PMDB), donde gobiernos, organizaciones y redes científicas han dedicado esfuerzos integrados para la resolución de los problemas ambientales.

Recientemente, se celebró en 2018 la $21^{\text {a }}$ Conferencia de las Naciones Unidas sobre el Cambio Climático (COP24) en Polonia, la cual repitió la dinámica de las grandes potencias y de los países emergentes que hablan sobre estos temas desde hace décadas, sin que haya ninguna acción real contra los contaminantes y culpables. Tal vez por eso el Papa Francisco, líder d la Iglesia Católica, utilizó este asunto para la encíclica Laudato si, que traduce "Alabado seas' y que llevó el subtítulo "Sobre el cuidado del hogar común"; en ella criticó el consumismo y el desarrollo irresponsable, y convocó a la unificación mundial de acciones para combatir la degradación ambiental. Sin sobrestimar cualquier mensaje religioso o moral, la encíclica Laudato Si tiene valor porque el ecologismo y el humanismo, al parecer, pasaron a ocupar un lugar destacado en la doctrina social de una religión influyente.

Ahora bien, es loable que la mayoría de los gobernantes se opongan al calentamiento global. Pero los científicos y juristas precisan conocer las pruebas del cambio climático con los datos que asocian la destrucción del medio ambiente con la apatía, las exageraciones en la búsqueda de ganancias y la creencia excesiva en la tecnología. Es una lástima que la visión de la polución global no abordó las relaciones humanas que, siendo un problema grave y universal, tiene serias implicaciones para el progreso social, económico y político de todas las generaciones. De hecho, no se han enfrentado los problemas ambientales sin primero distribuir o democratizar las riquezas.

Lo más destacado de los estudios sobre la protección de los ecosistemas es que no se puede perder de vista la revisión del papel de los combustibles fósiles, así como fijar una obligación moral y jurídica de los países industrializados, los cuales deberían ayudar a los países en desarrollo en 
la lucha contra las crisis financieras y el cambio climático. La ascendencia espiritual de las virtudes que se tiene a millones de personas puede ser un paso para cambiar la falta de conciencia real respecto al cuidado mutuo de las personas y de los países (Yardley, 2015).

En referencia a nombres fijados en notas humanísticas, y tal como sus predecesores, -a excepción de los Papas Juan Pablo II y Benedicto XVI, citando incluso a Aquino, Teilhard de Chardin, Romano Guardini y Ali al-Khawas (mística islámica del siglo IX)- la reflexión acerca de las fuerzas de ese aspecto es útil y válida porque también abarca otra serie de temas como la planificación urbana y la economía agrícola. La agenda de la biodiversidad podría contribuir más allá del conservadurismo místico, presentándose en posiciones científicas materiales concretas. Así, la posición de la iglesia frente a la anticoncepción, en los debates bioéticos y los problemas de las ideologías sexuales o de género, no vale si se niegan los mensajes antropogénicos de controversia en el orden jurídico. De ahí se exige una reedición de la filosofía científica que ya se conoce desde hace tiempo, en la cual se acentúa el problema del medio ambiente, pero es la economía mundial la que ha arruinado la perspectiva de cooperación de la humanidad.

En el derecho ambiental internacional actual, la ideología verde, que es el ecocentrismo, ha llamado la atención de los políticos y de los científicos, especialmente sobre la necesidad de transitar hacia una "economía baja en carbono".

En este contexto Canadá, Japón, China y la Unión Europea se han comprometido con tomar decisiones para financiar los programas de protección de la biodiversidad natural y física, mientras hoy no hay nada en concreto a favor de los países y pueblos más vulnerables que sin empleos o ingresos prueban que la decantada "sostenibilidad" es un espejismo que no detiene la pobreza (Gosepath, 2013, pp. 79-80).

Aunque la resolución del problema ambiental no pasa por ninguna teología ni estudio filosófico, la advertencia es planteada por el "mensaje capitalista" que tiene interés primario en la obtención de ganancias e intereses como retos de las élites mundiales, lo cual retrata la falta de una postura que atienda las necesidades de todos los pueblos. Por ello existe peligro de extinción de la humanidad. La miseria selectiva también es nociva al planeta, en la medida que provoca desigualdades e intolerancias que incitan los conflictos, las tensiones sociales, las violencias y las olas de terrorismo.

\section{PRECOCIDAD DEL BRASIL Y LEGISLACIÓN ARGENTINA EN MATERIA AMBIENTAL}

En América Latina la preocupación por el fenómeno del medio ambiente se produjo por primera vez en Brasil con la Constitución de 1824, la cual prohibía la instalación de industrias que afectaran la salud de los ciuda- 
danos. Sin embargo, con la promulgación de la Ley 6.938/81 (Congresso Nacional do Brasil, 1981) y tras el Decreto 99.274/90 (Presidencia da República do Brasil, 1990), el sistema legal brasileño proclamó que toda persona tiene derecho a un medio ambiente equilibrado, el cual es de uso común y esencial para una calidad de vida saludable, con la obligación impuesta de defenderlo para las generaciones presentes y futuras. Inaugurada la Política Nacional del Medio Ambiente junto con la Constitución de 1988, Brasil sellaba el principio de respeto a la integridad y dignidad humana, seguido por la propuesta de Argentina que se publicó en noviembre de 2002; a saber, su Ley General Ambiental 25.675 (Senado y Cámara de Diputados de la Nación Argentina, 2002). Estos temas ya eran tratados de forma general por Panamá en 1972 y Perú en 1979.

\section{TIPOS DE MEDIO AMBIENTE EN LA CONSTITUCIÓN BRASILEÑ A}

La noción actual de medio ambiente extrapola los aspectos geobiológicos, pero la Carta Federal de Brasil amalgamó otras modalidades ambientales, tales como el "medio ambiente artificial" que comprende los procesos de urbanización (art. 182, $\$ 2$ y la Ley $\mathrm{n}^{\circ} 10.257 / 01$ ) (Congresso Nacional do Brasil, 2001), vinculados a la función social de la propiedad rural (art. 186 II); el "entorno cultural", como resultado de las intervenciones humanas tangibles e intangibles, con especial valor asociado a la identidad, la memoria y la acción de los diversos grupos de la nación o sociedad brasileña, que abarca sitios arqueológicos, históricos, artísticos, naturales, ecológicos, las reminiscencias de los quilombos y los derechos indígenas (art. 216 y 231); y finalmente, el "ambiente laboral" previsto en los art. 200, II y VIII, y 225, VIII, que proporcionan los estándares cuantitativos y cualitativos de trabajo adecuado.

Eso significa que el derecho a un medio ambiente ecológicamente sano y de calidad no es limitado y requiere que el gobierno y la comunidad tengan una dimensión científica real y muy completa sobre el tema en cuestión. Entre tanto, esas normas no encajan bien con la idea de desarrollo sostenible si el país, de hecho, no se ha industrializado ni tiene cuidado con los temas de empleo de la distribución de ingresos y oferta efectiva de un orden jurídico realmente justo.

\section{ABORDAJES COMUNES E INUSUALES DEL AMBIENTA- LISMO CAPITALISTA}

En los círculos gubernamentales, en las cadenas productivas, en los estudios y en el radio de acción de las autoridades y de los órganos estatales, los ambientalismos se han concentrado principalmente en las siguientes áreas: racionalización del uso del suelo, el subsuelo, el agua, el aire y los árboles; la planificación y control en la utilización de los recursos para la protección de los ecosistemas; la preservación de áreas representativas; la zonifica- 
ción de actividades que sean potencial o verdaderamente contaminantes; las ayudas a las investigaciones en tecnología miradas en este sector; y la recuperación y protección de las zonas amenazadas por la degradación.

Es decir, incluidos los modelos de valoración de la seguridad y de la salud, además de dicha legislación especializada, los sistemas ambientales tradicionales recalcan solo elementos naturales del entorno para explicar la coexistencia de la corteza terrestre: la atmósfera, la fauna, la flora, la biodiversidad y las condiciones materiales del planeta. Por lo demás, se relegan a un segundo plano los factores dependientes del ambiente humano.

El conocimiento y los recursos plantean un modelo que solo se interesa por la salubridad y la seguridad. Bajo esta perspectiva, no se prioriza la dignidad de la persona como hombre ni como profesional, aunque esté dotado de características psicofisiobiológicas. Por ello, sería menester un enfoque jurídico y una tutela interdisciplinaria integral en cuanto a las cualidades espirituales del hombre.

Por otra parte, la vertiente de los ambientalistas alardea, de forma equivocada, sobre el riesgo del fin de los recursos naturales en los países no industrializados o emergentes, delante de una situación singular paralela que lleva a las potencias a explotar los bienes económicos apreciables de los países más pobres, al mismo tiempo que se toman o se les permite el control de las políticas ambientales y económicas de estas naciones no contaminantes, a través de fallos políticos, culturales y jurídicos que cuentan asimismo con el apoyo mediático, bajo el pretexto de contribuir a la "sostenibilidad" del planeta.

Sin garantizar a esos pueblos las condiciones mínimas para alcanzar el progreso, a los enfoques ambientales importan más los aspectos ecocéntricos puros. Las propagandas de conservación de la biota son muy retóricas porque atienden las conveniencias de quienes no quieren proveer las mejoras físicas y humanas de las regiones y de las poblaciones que viven al margen de los ciclos de civilización. El "ecoambientalismo", por supuesto, esteriliza las dignidades humanas, no ofrece empleos ni ingresos y, por tanto, pareciera un artificio sutil de los países más avanzados para mantener intacto el pacto implícito y estratégico del "neocolonialismo".

\section{SISTEMAS TRADICIONALES LATINOAMERICANOS DE GESTIÓN AMBIENTAL}

Las preferencias demostradas por el derecho capitalista son las reglas y criterios de sentido naturalista o patrimonial, pero los numerosos modelos ambientales, fabricados en el ámbito internacional, no signan una idea de preocupaciones sobre las cuestiones del "humanismo relacional". Las investigaciones existentes excluyen las asignaciones y responsabilidades de los países que contaminan el medio ambiente, incluso sus teorías niegan 
oportunidades de mejoría de otras naciones que no han acumulado tantos capitales volátiles en los mercados financieros ni en los paraísos fiscales.

El "ambientalismo capitalista", por tanto, no tiene en cuenta los rasgos de los sistemas que defienden los derechos biopsicologicos y los ingresos de la gente que precisa vivir a través de prestaciones laborales para que los hábitats humanos se tornen más sostenibles. En este paso, el propio derecho elitista ha producido ambientes de trabajo que son solo más lugares donde se ejerce una determinada actividad profesional; estos podrían ser transformados en hogares a partir de los cuales se pudiera promover la salud o posibilitar que se realicen también los planes de asistencias existenciales, individuales y colectivos a partir de un mirada en la búsqueda por el bienestar de los obreros y sus familias.

El análisis inusual sobre el medio ambiente se define por un concepto más amplio que abarca el bienestar personal, con énfasis en aspectos de los derechos psicofíicicos desde la práctica de políticas más humanistas, justas y saludables. En este eje, los tratamientos, las cooperaciones y las interacciones entronizan los espacios de derechos que refutan las contaminaciones humanas. Por lo que es posible admitir una gestión ambiental integral y no selectiva que debe imponerse al gobierno, en tanto las plenitudes antropogénicas deben abrazar las comunidades, las organizaciones y las ciudadanías hacia la concreción de un mundo más ecuánime y eudaimónico.

Por otro lado, a despecho de la variedad inmensa de intereses de las personas y de los países, hay métodos y teorías que pudieron desarrollar los derechos de educación, seguridad y salud de los individuos desde el planteamiento de una ética de contenido ideológico fuerte, si bien los actos, las actitudes y los procedimientos de países y personas que pueden contribuir con los derechos materiales y espirituales son aún muy tímidos.

En esta situación, las doctrinas nacionalistas y los patriotismos extremistas deben ceder lugar a las prácticas virtuosas, como las vivencias mutuas más significantes y cooperativas entre los pueblos y países en que la existencia útil y racional convengan en actuaciones personales o de poblaciones hacia la realización de la globalización del bienestar individual, social y laboral, solo entonces habrá sostenibilidad real.

\section{LA OBSOLETA Y RETRASADA FILOSOFÍA AMBIENTAL LATINA Y BRASILEÑA}

En el marco de una visión revolucionaria del crecimiento y de las integraciones entre las soberanías de los países, la promoción, control, supervisión y ejecución de las relaciones ambientales en Brasil no se entienden en su sentido más amplio, es decir, excluyen el derecho a ambientes relacionales o laborales emocionalmente estables, equilibrados y sostenibles. A pesar de la disposición constitucional brasileña de que la salud no es 
un favor, sino un verdadero poder y un deber de todos, los titulares del capital y del poder aprovechan la energía psicofísica de los trabajadores o promueven el desempleo en masa, imponiendo dramas, ansiedades y dolores en las vidas de muchas familias.

Ahora bien, además de las reglas de la Política Nacional de Seguridad y Salud en el Trabajo, obsérvese que, en la esfera de la gestión ambiental, el Brasil utiliza la Ley $n^{\circ}$ 6.938/81 (Congresso Nacional do Brasil, 1981) que en su artículo $3^{\circ}$ define el medio ambiente en su connotación física, mientras la Constitución considera de importancia pública acciones y servicios de salud al indicar las responsabilidades gubernamentales. En este contexto, las leyes brasileñas no han establecido correlaciones íntimas entre el medio ambiente y la preocupación por la total integración de las relaciones humanas sanas y el bienestar psicológico en el área de la salud ocupacional y existencial, excepto en términos más figurativos.

La implementación de políticas de gestión ambiental es hecha por el Estado y por personas físicas o jurídicas de derecho privado que, sin embargo, cubren solo la atención de salubridad de los locales. El cuidado con el clima organizacional o con el estado -individual y colectivo- de las personas no es todavía prioritario.

El derecho a un ambiente sostenible no se garantiza ni se asegura con promesas. En teoría, es un axioma constitucional (en el peor de los casos, implícito), un derecho singular en su carácter dirigido a las generaciones actuales y futuras; un bien jurídico difuso, de interés metaindividual que, por su altitud, implica procesos de paz y el orden social. Esta herencia que añade una gran cantidad de valores materiales e inmateriales es concebida por pocos, pero configura los problemas más comunes que afectan a la salud y a la seguridad de las personas. Además, la omisión o aparente brecha de integración del medio ambiente con los derechos de supervivencia humana no son solo materiales sino espirituales, porque no hay políticas para el progreso y la realización de todos. La propia falta de claridad de la Ley 9.795/99 (Congresso Nacional do Brasil, 1999) brasileña sobre estas cuestiones deja en claro el error de la educación ambiental local que no incorpora políticas públicas.

Para la aplicación de las complejas soluciones de desarrollo social, la legislación latina se preocupa más con principios de compensación o mandamientos de prevención y de precaución: mensajes de "quien contamina-paga”. Habla de restitución más en la cara de las lesiones al medio ambiente en actividades ilegales de la mano de obra civil y otras, haciendo hincapié de las infracciones, pero no enfrenta los factores de los daños que los países más ricos han ya provocado a la naturaleza y los largos perjuicios que otras naciones industrializados son responsables desde los años pasados.

Sin embargo, en otro sentido diseñado para tareas ordinarias y siendo de poca importancia práctica, el Estado brasileño, además de todo el derecho 
ambiental de los países pobres, se rige por normas objetivas ambientales que requieren la existencia de un entorno saludable desde un punto de vista físico, cuando en realidad la democratización del acceso a los bienes materiales y a la justicia ambiental solo desempeña un papel que en la práctica no ha restaurado las políticas de garantía concreta de dignidad para todos.

En el artículo 170 de la Constitución Federal de Brasil (Asamblea Nacional Constituyente, 1988), la interdicción estampada en el artículo 161 de la CLT, la obligación de indemnización por daños ambientales del artículo 927 de su Código Civil, las disposiciones que protegen a las mujeres, expuestas en el artículo $7^{\circ}$, inciso XVIII y en los artículos 372 al 401 del Código de Trabajo, la protección especial de menores del artículo $7^{\circ}$, XXXIII de la Constitución y los artículos 60 y 69 de la Ley no 8.069/90 (Congresso Nacional do Brasil, 1990), la prohibición expresa de prácticas discriminatorias por la Ley $\mathrm{n}^{\circ}$ 9.029/95 (Congresso Nacional do Brasil, 1995), los crímenes ambientales definidos en la Ley no 9.605/95 (Congresso Nacional do Brasil, 1995), el "programa ciudadano corporativo" (Ley $\left.n^{\circ} 11.077 / 08\right)$ (Congresso Nacional do Brasil, 2008) y otros puntos de su legislación, salvaguardan más la condición física y los valores ecológicos que propiamente las condiciones de desarrollo humano pleno y real.

Las cuestiones ambientales también reciben un tratamiento especial en las Comisiones Internas de Prevención de Accidentes y, para las personas con discapacidad, la Ley $\mathrm{n}^{\circ}$ 7.853/89 (Congresso Nacional do Brasil, 1989) ofrece lugares laborales, maquinarias y mobiliarios sujetos a tutelas ambientales especiales, favoreciendo el alojamiento, la salud y el bienestar. En esta red están dichas "normas reglamentarias" que tratan de productos, sustancias y servicios pertenecientes a varias actividades profesionales, con una lista de providencias que permiten la mejora de la seguridad y salud física en el trabajo, la disminución de los riesgos o la eliminación de las amenazas de peligro para el trabajador, además de reglas para evitar sus exposiciones excesivas, en especial de las profesiones consideradas más insalubres, con las hipótesis del uso de algunos equipos individuales obligatorios. La bandera de la sostenibilidad ambiental en boga no cubre pues la inclusión financiera y social, ni políticas públicas y privadas que prioricen un desarrollo antropogénico total.

\section{ENFOQUES DEL BIENESTAR GEOPOLÍTICO DE LAS RE- SOLUCIONES DE LA ONU}

El Estado Ambiental para el progreso de los países latinos es, en parte, una farsa, porque los ricos no respetan la Declaración Universal de los Derechos Humanos de la ONU (Resolución 217 A III, de 10 de diciembre de 1948) que en el artículo XXV fijó que todo ser humano tiene derecho a un nivel de vida adecuado para uno y su familia, con salud, bienestar, alimentación, vestido, vivienda, asistencia médica, servicios sociales necesarios y seguros en caso de desempleo, enfermedad, invalidez, viudez, 
vejez u otros casos de pérdida de los medios de subsistencia por circunstancias independientes de su voluntad.

Consciente de la metamorfosis de los derechos sociales, ahora es necesario la aplicabilidad de la teoría de la garantía del mínimo existencial posible (Scholler, 1980, p. 676; y Zacher, 1987, p. 1062), toda vez que en 2011 la Asamblea de la ONU promulgó la Resolución 65/309 que aborda la felicidad como un interés cosmológico para dirigir la fundación de un nuevo orden mundial general. No obstante, ese documento tiene aún varias directrices superficiales y carentes de notas de coercitividad, al igual que la Resolución 1803 (ONU, 1962) que es una recomendación emblemática de gran valor histórico que contiene solamente mensajes indicativos y sin efectividad. Por tanto, en cualquiera de los casos, entre muchos otros, estas iniciativas son formales y no se han revelado suficientes para deshacer los desequilibrios colosales de naciones y pueblos "dependientes" del capital externo, al experimentar mucho dolor y sufrimientos.

La ideología ambiental brasileña es una animación, que precede vectores preferiblemente naturalistas, poco se dice, se estudia o se produce en la región sobre las "contaminaciones relacionales interhumanas". Por lo que la idea de "sostenibilidad" no pasa de una bandera o un cálculo para la preservación o el aumento de la hegemonía de las ganancias y lucros, sin tornarse en un marco de progreso, sino que representa retraso geopolítico y asimétrico de desarrollo entre los países en el mundo.

Con el aspecto destacado físico y natural de las cuestiones ambientales, hay todavía otro punto que es de suma relevancia para la construcción de una tesis en torno al perfeccionamiento de las medidas de profundización de relaciones humanas para integrar los habitantes del planeta. En efecto, los derechos de dicha Resolución 1803, al proponer y referirse a las posibilidades de las personas para desarrollar sus potencialidades existenciales trae un mensaje puramente educativo, mientras el progreso de los pueblos no se resume a un contenido biológico formativo sin sentido si los Estados ricos no celebran alianzas de una juscooperación internacional que rechace el modelo actual.

\section{EL ESTADO DE DERECHO AMBIENTAL Y LAS PERPLEJI- DADES NACIONALES}

Cuando se hace referencia a la Carta Magna brasileña, algunos usan el lujoso término "Estado de Derecho Ambiental" porque el estándar escogido produjo varios tipos de derechos y competencias en estas materias que son distribuidas en muchos de los niveles y esferas de poder (art. 20, LI, 23, VI y VII, y 24, VI, VII y VIII, la CF/88). De acuerdo con otras fuentes, aún hay varias normas técnicas sobre temas ambientales relativas a las políticas de prevención, control de la salud, bioseguridad, gestión del tratamiento de residuos sólidos y líquidos, entre otras medidas vinculadas 
con la fisiología humana, como el fuego y la higiene que fueron impuestas a los entornos institucionales y empresariales para crear un mensaje de bienestar material sostenible.

Los procedimientos de inspección, las investigaciones de violaciones y la aplicación de sanciones administrativas también se revelan extensos y multitudinarios en el conjunto de políticas y prácticas exigidas al Estado y a los sectores privados que tienen en cuenta la protección de dichos ambientes equilibrados. La sostenibilidad ambiental laboral, sin embargo, aún es poco respetada en su rango biopsicosocial. Por ello, el estudio considera importante evaluar no solo las recomendaciones de la ONU, que definen un entorno de trabajo seguro, así como una tesis que active la colaboración de jefes, trabajadores y sus familias en procesos de constante mejora y cooperación. La ponencia sobre seguridad, salud y bienestar de todos los obreros va, por tanto, más allá de dicha sostenibilidad del medio ambiente laboral (Convenio 155, OIT) para rechazar de todas formas los modelos egocéntricos y narcisistas del capitalismo financiero, y aportar reclamos contra un ambientalismo que impida el crecimiento de todos los pueblos.

Pero el orden ambiental de los países latinoamericanos no suele aplicar la correlación de los problemas de seguridad civil, laboral o familiar con elementos de los derechos psicofísicos y sociales que se originan y se demandan a las entidades y a los Estados respecto del deber de cumplir la disposición de una cultura ética oficial que contemple recursos destinados a las acciones de desarrollo en esta área.

En cambio, el "Estado de Derecho Ambiental latinoamericano" proclama la salubridad de los aspectos físicos de los entornos, pero no obliga entornos saludables en cuanto a la inclusión de factores psicosociales y a las actividades de prevención de la salud del trabajador individual y de otros agentes de los sectores productivos, siendo omisa principalmente en cuanto a las cuestiones de empleos y distribución de ingresos

\section{LAS PERSPECTIVAS DE LOS DERECHOS Y OBLIGACIO- NES AMBIENTALES EN EL MUNDO}

Ya se probó que el ambientalismo internacional dominante hace referencia solo o predominantemente a la protección de los aspectos físico-naturalistas de la biota y asimismo poco se dijo o tampoco se producen datos científicos sobre las "poluciones ambientales relacionales" debido a la primacía del interés por las ganancias. Los PIB's per cápita de las potencias son por eso proporcionales a los retrasos y a las dependencias económicas de otros países cuyas reservas monetarias ya fueron minadas y que no se expanden ahora debido a movimientos que fijan ponencias y criterios con marcos más ambientales y ecológicos. 
Las naciones ya industrializadas, a su vez, insisten paradójicamente en anunciar la necesidad de la sostenibilidad sin haber cumplido antes los ideales de preservar los ecosistemas, por lo que se lanzan numerosas frases y repetidas alusiones de inminentes tragedias físicas que no han sido provocadas por los países pobres. A continuación, los científicos sociales y la prensa suelen informar, en cambio, sobre los asuntos ambientales a través de expresiones comunes asociadas con un lenguaje más restricto de la naturaleza, usando palabras como "prevención", "impactos", "accidentes", "equilibrio" y "contaminación”, siempre en la procura de responsabilidades. Este hallazgo se complementa con la difusión de códigos de la silvicultura, la pesca, las aguas, la minería y otros dichos legales sobre "diversidad biológica", sobre la "protección de parques" o la conservación de los "bienes naturales".

Sin embargo, se observa más el aspecto físico-natural del medio ambiente, a pesar de la existencia del entorno artificial, cultural y laboral. La idea de educación relacional no es un mensaje de la Resolución 1803 de la ONU que plantea el desarrollo sin apoyar los países ubicados en las regiones más pobres. El capitalismo, basado en las hegemonías financieras, desconsidera las oportunidades de progresos en la construcción de una nueva categoría científica para el medio ambiente, las ciencias del derecho, la Economía, la psicología, al psicoanálisis, la medicina y otros tipos de conocimientos y de gestiones, para que los problemas relacionales del hombre y de las naciones se conviertan en activos financieros beneficios para pocos.

La ideología mundial que instruye el pensamiento ambiental es una estafa, un camino al crecimiento de los pueblos y personas adineradas, en la medida que impide la afirmación de un gran progreso material, prosperidad e integración espiritual de todos, lo cual estimularía el "máximo existencial", por lo que latinoamérica no debería, en principio, seguir las directrices y los protocolos globales del ecologismo sin recibir cualquier compensación financiera a su favor.

En este contexto, en el cual se ponen en jaque las doctrinas internacionales que en esta área han proporcionado políticas de retrasos y de recesión, muchos juristas han abogado por políticas ambientalistas tradicionales, es decir, las que no respetan la lógica integrativa de los ciclos civilizatorios. Sin aplicar un "choque real" en el academicismo pro-homo ambiental y en la forma de organización de las finanzas mundiales, cualquier concientización ecológica es inútil, sobre todo en los países más pobres, pues continuará produciendo millones de víctimas y paralizando los procesos de emancipación de la gente.

La advertencia es una reflexión frente a los intereses del neocolonialismo en curso que precisa, sin embargo, de estudios complementarios, dada la profundidad y complejidad de la materia. La verdad es que los pen- 
samientos científicos sobre el tema han monopolizado las ganancias e intereses personales, sobre todo cuando se trata de expresar "lemas" que ya se tornaron "jergas" internacionales con la bandera de la sostenibilidad ambiental. Pero el drama se desnuda al corroborarse que no hay aún mecanismos concretos para la inclusión financiera y laboral en el planeta a los más necesitados, sino medidas geopolíticas que tienden a clamar deberes, mientras los paradigmas no se convierten en garantías existenciales para todos. La "jurisciencia" de la élite mundial, por tanto, indica los caminos mediáticos para el desarrollo de los más vulnerables que no suceden porque son frutos de los simulacros intelectuales y de las contradicciones que rodean las causas ambientales. Resultan estériles las promesas políticas de créditos de carbono establecidas en las conferencias de Joahnnesburg en Sudáfrica y de Bonn en Alemania en 2001.

Al no crear ni distribuir riquezas en los países más pobres, ese modelo ambiental, que es francamente alienante, neutraliza las dignidades humanas. La falta de acceso de poblaciones hambrientas a los trabajos y a las tecnologías no les permite el constructo de nuevos hitos socio-económicos, lo cual acarrea ruina en las condiciones de vida de esas generaciones. La estructura de las actividades agrícolas, la pesca y las actividades productivas se sujetan ahora a todos tipos de límites y perjuicios de la legislación ambiental que, en la práctica, selecciona quiénes disponen del potencial económico y financiero para invertir en dichos proyectos y comunidades ambientales.

Sin oportunidades de empleo o de ingresos para sobrevivir, la gente pobre de otros países queda obligada a un destino doméstico desgraciado y no hay manera de compensar los dolores de esos pueblos históricamente explotados, excepto si existiera la institución de pago de "créditos existenciales" como una novedad para garantizar la globalización del bienestar o, al menos, disminuir los graves problemas sociales.

El hecho es que la cuestión ambiental provoca una parálisis forzada del progreso y los esfuerzos de soporte de los países aún industrializados no son efectivos.

Recuérdese que las resoluciones de la ONU 523 (VI) del 12 de enero 1952 y 626 (VII), de 21 de diciembre de 1952, propusieron en Bonn, en 2001, una forma de incentivo económico para los países de bajos ingresos que a cambio de la conservación de sus bosques recibirían los créditos de carbono que serían activos otorgados a los países que se comprometieran a usar Mecanismos de Desarrollo Limpio (MDL) para la reducción de sus emisiones de dióxido de carbono, incluyendo las energías y fuentes renovables alternativas.

La propuesta que pretendía obtener la desaceleración de la temperatura de la Tierra a 1,5 grados para el año 2100 fue un fracaso, porque en la práctica, sin el apoyo de los Estados Unidos y China que son los princi- 
pales contaminadores del planeta, las políticas industriales y de consumo continúan agresivas y competitivas. Esta conclusión está bien perfilada incluso por el presidente de los Estados Unidos, Donald Trump, quien, aunque reconoce en parte el problema medioambiental, ha señalado que este problema no puede estorbar el progreso de su país. Por ello, las recomendaciones del PNUMA no deben sustituir el método del carbon sequestration financiado por los créditos de la Bolsa de Chicago, por lo que no se justifica cesar el nuevo avance social e industrial de esta gran potencia.

En este mismo renglón los países de la APEC, como Hong Kong, Tawain, Corea, Singapur, Filipinas y Tailandia, no han dado mucha importancia a las cuestiones de la sostenibilidad y los RCEs. En cambio, los habitantes de esta región vienen experimentando desde la década de 1980 un razonable progreso, al mostrar expresivas mejoras en sus Índices de Desarrollo Humano (IDH) y en los PIB's por renta per cápita.

El supuesto de pago de los sugeridos “créditos existenciales", a partir del momento en que un país no desarrollado deja de invertir en su industrialización, sería una forma de capturar el carbono de la atmósfera y al mismo tiempo una modalidad real de concretar los planes de una justicia biolaboral en el orbe internacional. De ese modo, aunque algunos países se mantengan financieramente "rehenes" de los más poderosos, esas medidas traerían la contaminación a niveles aceptables y el dinero destinado por los "créditos existenciales" habría de ser usado obligatoriamente en la oferta de empleos e ingresos en los servicios u otros sectores de apoyo a la economía mundial. Se cree pues que los "créditos existenciales" podrían integrar una partícula relevante de un derecho interconstitucional en formación, destacándose como una pieza monetaria para cambios o negocios en la extensa categoría en evolución de nuevos bienes y valores.

\section{CONCLUSIONES}

Con métodos descriptivos, inductivos, deductivos y consultas bibliográficas, este breve estudio incluyó algunos conocimientos teóricos y prácticos sobre los pasos de la Constitución y legislación ambiental brasileñas que están de nuevo al orden del día en las conferencias y reuniones sobre el cambio climático de la ONU de 2019 cuyo inventario no exclamó ninguna gran ayuda concreta para el mundo en desarrollo.

A pesar de ser uno de los pioneros en materia de medio ambiente, los sistemas de gestión ambientales de la Constitución de 1988 de Brasil, los cuales son seguidos en América Latina por las imposiciones del capitalismo exploratorio, favorecen todavía más al fisiocentrismo. Pero ese ecocentrismo exagerado ha constituido, paradójicamente, un obstáculo cierto para el progreso y el crecimiento de las naciones de aquella región. 
La insostenibilidad del modelo ambiental brasileño tiene enfoques erróneos o incompletos sobre la materia y no hay duda de que las leyes de educación ambiental de aquellos países no están totalmente actualizadas. Ahora bien, no se puede imaginar un Estado Ambiental sostenible que no sea benéfico en el sentido económico y social.

Así, el ambientalismo brasileño, como el de la mayoría de los otros países de latinoamérica, se ahoga o se asfixia por programas de custodia de la biodiversidad natural que es capitaneado por las naciones más ricas que anuncian una tragedia global inminente, sin ofrecer ninguna salida estratégica o asertiva sobre el fin del desempleo y el estancamiento de la pobreza de sus pueblos. Para agravar este escenario, además de la omisión y la indiferencia de las grandes potencias que hacen promesas despojadas de fuerza ejecutiva o sancionatoria, las comunidades políticas internacionales no producen paradigmas que contemplen fallos concretos de desarrollo humano. La verdad es que hasta los científicos y los académicos no han formulado patrones de cambios evolutivos realistas sobre las políticas del medio ambiente que estancan el progreso.

El Río 92 así como la Constitución de Brasil son ejemplos medulares de una promesa de protección ambiental de valor semántico que, a pesar de su exuberancia formal, no han servido para promover el crecimiento eficaz de las naciones y de la gente del entorno del continente sudamericano, ensanchando, al contrario, la descomposición social, familiar y económica de los pueblos que viven allá. Mientras que los países más avanzados y el capitalismo financiero asimétrico burlan la lógica integradora de los ciclos civilizatorios, las condiciones de vida y las relaciones interpersonales entre los países se precarizan. Hoy la conciencia del homo ambiental es asimismo una estafa.

De todos modos, en parte, el ambientalismo brasileño es una farsa intelectual y, en un análisis geopolítico, los países pobres o emergentes tienden a imitar esta trampa de derechos y obligaciones dictadas por el mundo del derecho ambiental mundial, cuyos estudios preliminares indican que estos estándares son factores que impiden el desarrollo y el progreso existencial, especialmente de los países más débiles del planeta. El objetivo es la continuación perenne del "neocolonialismo" de Latino América.

En efecto, la hermandad, la solidaridad y el cooperativismo son ideales muy difíciles de alcanzar en esta era, pues fueron esas mismas construcciones hegemónicas las que en el pasado legitimaron la esclavitud y el racismo, y justifican la desigualdad hoy al defender el neocolonialismo, las crisis y las recesiones de los países más pobres.

La situación de proliferación del desempleo y la precariedad del trabajo en las regiones más pobres del planeta resulta una inaceptable conmoción ambiental. Con esta traba, las personas no flotan en las estructuras 
sociales, la función integradora de los jóvenes falla, hay una caída de salarios y siquiera hay ventajas de los profesionales cualificados. Al provocar daños incrustados hoy inclusive en los tejidos familiares, ese momento histórico, si irreversible, producirá efectos desastrosos desde el punto de vista económico de la cohesión mundial. Asimismo, la disminución o la desaparición de los recursos no justifica el vaciamiento de medidas alternativas y la escasez de políticas de compensaciones de cambio de las normas y modelos ambientales que esterilizan rentas y que, en consecuencia, frustran la distribución de los ingresos en el mundo.

Frente a esas conclusiones, se observa la necesidad de un "corte epistemológico" en los pensamientos y acciones de las corrientes jurídicas actuales que tengan en el trabajo los paradigmas útiles para una metamorfosis social. Aunque la competitividad y la conflictividad sean elementos constitutivos innatos de la vida social, la solución y el uso de una biopolítica global no harán la invocación de milagros o de principios de bondades en las esferas regionales si, en esta línea, los dilemas laborales, ambientales y comunitarios no se solucionan antes que se acabe con la humanidad. Se resalta que no hay la idea de un capitalismo democrático que garantiza el "mínimo" de los derechos sociales fundamentales a la vista de la supremacía de la dignidad humana.

Por eso, los estudios académicos filtran análisis políticos, económicos y sociales para aportar cuestiones que superen los mitos de la necesidad de conservación de la biodiversidad ambiental, el cual debe ser sustituido por biopolíticas de sostenibilidad globales reales, por algo que verdaderamente ponga el ser humano en el epicentro de la jurisciencia. En este sentido, el ambientalismo latinoamericano representa un retroceso para la continuidad de la colonización.

\section{REFERENCIAS BIBLIOGRÁFICAS:}

ASAMBLEA NACIONAL CONSTITUYENTE. (1988). Constitución Política de 1988 República Federativa de Brasil.

DA SILVA, José Afonso. (2003). Direito Ambiental Constitucional. $4^{\mathrm{a}}$ ed. São Paulo: Malheiros.

CONGRESSO NACIONAL DO BRASIL (1981). Ley No 6.938, de 31 de agosto de 1981. Recuperado de: http://www.oas.org/dsd/fida/ laws/legislation/brazil/brazil_6938.pdf

CONGRESSO NACIONAL DO BRASIL (1989). Ley No 7.853 de 1989. Recuperado de: http://www.ilo.org/dyn/natlex/natlex4.detail?p_ lang $=$ es\&p_isn $=57119 \&$ p_classification $=08.01$

CONGRESSO NACIONAL DO BRASIL (1990). Ley No 8.069 de 1990. Recuperado de: http://www.sipi.siteal.iipe.unesco.org/normativas/30/ley-ndeg-80691990-estatuto-del-nino-y-del-adolescente 
CONGRESSO NACIONAL DO BRASIL (1995). Ley No 9.605 de 1995

CONGRESSO NACIONAL DO BRASIL (1999). Ley No 9.795 de 1999.

CONGRESSO NACIONAL DO BRASIL (2001). Ley No 10.257, del 10 de julio de 2001. Recuperado de: http://www.hlrn.org/img/documents/el-estatuto-de-la-ciudad\%20sp.pdf

CONGRESSO NACIONAL DO BRASIL (2008). Ley No 11.077 de 2008.

GOSEPATH, Stefan. (2013). Uma pretensão de direito humano à proteção fundamental. En: TOLEDO, Cláudia (Org.). Direitos Sociais em debate. Rio de Janeiro: Elsevier.

ONU. (1948). Declaración universal de derechos humanos. Resolución 217 A (III), de 10 de diciembre de 1948. Recuperado de: http:// www.equidadmujer.gov.co/ejes/Documents/NormativaNacional/ Declaraci\%C3\%B3n\%20Universal\%20de\%20Derechos\%20Humanos\%20de\%201948.pdf

ONU. (1987). Our Common Future: Brundtland Report. New York.

ONU. (1962). Soberanía permanente sobre los recursos naturales. Resolución 1803. Disponible en: https://www.ohchr.org/SP/ProfessionalInterest/Pages/NaturalResources.aspx

PRESIDÊNCIA DA REPÚBLICA DO BRASIL. (1990). Decreto no 99.274, de 6 de junho de 1990. Dsiponible en: http://www.planalto.gov.br/ ccivil_03/decreto/Antigos/D99274.htm

SACHS, Jeffrey. (2015). The age of sustainable development. New York: Columbia University Press.

SCHOLLER, Heinrich. (1980). "Die Störung des Urlaubsgenusses eines 'empfindsamen Menschen' durch einen Behinderten”, en: Juristenzeitung.

SENADO Y CÁMARA DE DIPUTADOS DE LA NACIÓN ARGENTINA. (2002). Ley $\mathrm{N}^{\circ}$ 25.675, Ley General del Ambiente. Recuperado de: http://www.opds.gba.gov.ar/sites/default/files/LEY\%2025675. pdf

SILVA, Virgílio Afonso. (2005). A evolução dos direitos fundamentais: Revista Latino-Americana de Estudos Constitucionais. $6^{a}$ ed. Belo Horizonte. Del Rey.

YARDLEY, Jim. (2015). Pope Francis, in Sweeping Encyclical, Calls for Swift Action on Climate Change. The New York Times. 18 de junio de 2015.

ZACHER, Hans-Friedrich. (1987), "De las solas y Staatsziel", in: Isensee-Kirchhof (Org). Handbuch des Staatsrechts der Bundesrepublik Deutschland (HBStR), vol. I, Heidelberg, CF Muller. 